\title{
Discussion: Torsional behaviour of prestressed concrete girder with precast box segments
}

\author{
Min Sook Kim \\ PhD Candidate, Department of Architectural Engineering, \\ Kyung Hee University, Yongin, Korea
}

\section{Andrew Scanlon}

Professor, International Scholar, Department of Civil Engineering,

The Pennsylvania State University, University Park, PA, USA; Department of Architectural Engineering, Kyung Hee University, Yongin, Korea

\section{Joowon Kang}

Professor, School of Architecture, Yeungnam University, Gyeongsan, Korea

\section{Young Hak Lee}

Associate Professor, Department of Architectural Engineering, Kyung Hee University, Yongin, Korea

Jose R. Martí-Vargas

Professor, ICITECH, Institute of Concrete Science and Technology, Universitat Politècnica de València, Valencia, Spain

\section{Contribution by J. R. Martí-Vargas}

The discussed paper (Kim et al., 2014) presents an experimental study of spliced precast prestressed concrete girders to evaluate torsional performance, based on the method of connecting segments. Three types of joints were examined in terms of the crack and failure pattern, maximum torque $\left(T_{\mathrm{u}}\right)$, torsional stiffness and torsional ductility. The authors should be complimented for providing this detailed paper that is of interest to the discusser, who would like to offer some comments for their consideration and response, mainly about details of the specimens and test results.

Each specimen was fabricated by splicing two segments through steel box tubes inserted into hollow sections to improve girder strength. Two of the five specimens were designed by using steel tubes that differed in size: a $200 \times 200 \times 6 \mathrm{~mm}$ steel tube protruded from one concrete segment and a $186 \times 186 \times 6 \mathrm{~mm}$ steel tube was embedded in the other concrete segment. The authors state that the protruding steel tube was inserted into the other steel tube. However, it seems that the protruding steel tube should be the smaller one rather than the bigger one, and that the hollow section of the corresponding concrete segment should be $186 \times 186 \mathrm{~mm}$ instead of $200 \times 200 \mathrm{~mm}$, as shown in Figure 2 in the paper. Furthermore, the discusser believes that the difference in size results in a gap of $7 \mathrm{~mm}$ between the two steel tubes on all sides (if a perfectly centred insertion is assumed). This may result in a certain limitation in terms of the collaboration of the two steel tubes until a considerable twist angle is achieved. Perhaps this may explain the lowered torque upon crack occurrence in the two SGI specimens, and also the fact that there is no reason for a lower crack load (36 versus $43 \mathrm{kN}$ ) when a longer overlap length (600 versus $300 \mathrm{~mm}$ ) is used.

The crack patterns are shown in Figure 4 in the paper. However, the discusser could not find the locations of the overlap lengths in the SGI specimens and the length inserted into the SGC specimen. In order to offer a better understanding, can the authors provide additional details on these issues?

Ductility performance was evaluated through the ratio $\phi_{0.8 \max } / \phi_{\mathrm{cr}}$. The discusser is confused about the two definitions of $\phi_{0.8 \max }$ : the twist angle when the initial angle reached $0 \cdot 8 T_{\mathrm{u}}$, and the twist angle when the initial angle of $\phi_{\mathrm{cr}}$ reached $T_{\mathrm{u}}$, and then the torque maintained at $0 \cdot 8 T_{\mathrm{u}}$. Furthermore, in Figure 6, the torque-twist curves for specimens SGI and SGC differ from those for specimens $\mathrm{MG}$ and SGW: the former display a softening branch where point $0 \cdot 8 T_{\mathrm{u}}$ is identifiable, whereas the latter depict a practically horizontal branch after $T_{\mathrm{u}}$ is reached. One main result is that the ductility of specimen SGW is about $40 \%$ higher than that of specimen MG. However, it seems that the $\phi_{0.8 \max }$ values in Table 6 do not correspond to $0 \cdot 8 T_{\mathrm{u}}$ for specimens $\mathrm{MG}$ and SGW. It is noteworthy that: the value $0.0449 \mathrm{rad} / \mathrm{m}$ for specimen $\mathrm{MG}$ is near the twist angle at $T_{\mathrm{u}}$; the value $0 \cdot 0640 \mathrm{rad} / \mathrm{m}$ is not depicted in the SGW curve; and, according to the abstract, specimen SGW had around five

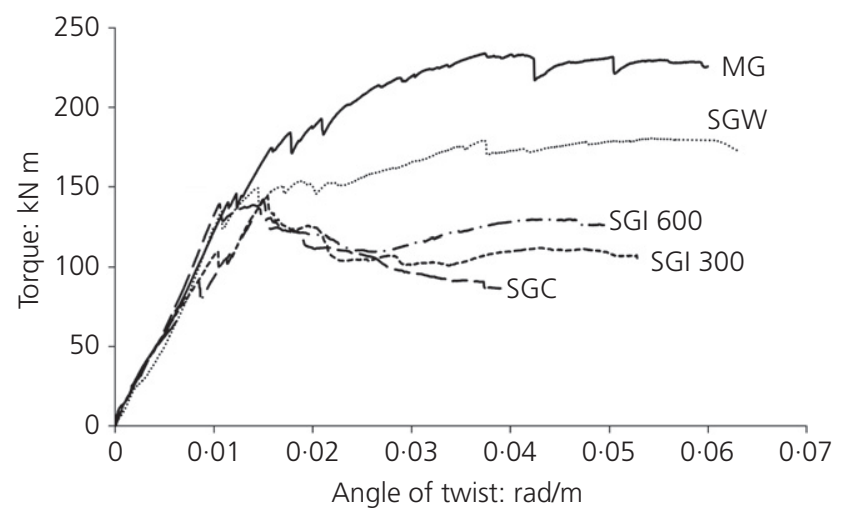

Figure 2. Torque versus angle of twist 
times the twist angle compared with the other specimens, which seems an unsupported result. These points should be clarified.

\section{Authors' reply}

The authors appreciate Professor Martí-Vargas' interest in the paper and his discussion comments. The three issues he raises are discussed below.

(a) The inside dimension of the larger tube was $188 \mathrm{~mm}$ and the outside dimension of the smaller tube was $186 \mathrm{~mm}$, leaving a nominal $1 \mathrm{~mm}$ gap all around. This produced a tight fit, and no 'take-up' was observed on initial application of the load. The post-peak softening response was likely affected by relative slip between the tube surfaces at the splice as the deformations increased. (b) As requested, we have added the locations of the splice details to Figure 4 as shown here in Figure 1.

(c) To evaluate the ductility performance, a ductility index $\mu$ was calculated as the ratio $\phi_{0.8 \max } / \phi_{\mathrm{cr}}$, where $\phi_{\mathrm{cr}}$ is the twist angle upon crack occurrence and $\phi_{0.8 \max }$ is the twist angle occurring when the torque dropped to $80 \%$ of the maximum torque in the post-peak range. This definition was applied directly to the SGI and SGC specimens, which displayed significant post-peak softening immediately after reaching the maximum torque. However, for the MG and SGW specimens the test was terminated before the load dropped to $80 \%$ of the maximum torque. Therefore, in these cases, the angle of twist occurring at $90 \%$ of the maximum torque was used as a conservative value for ductility. In Figure 6, some of the data points

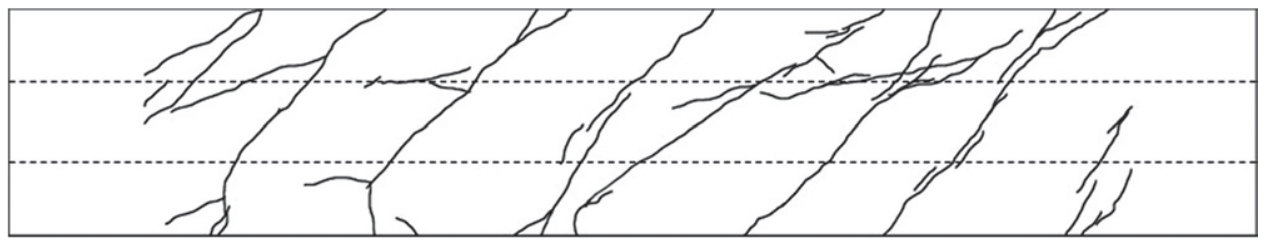

(a)

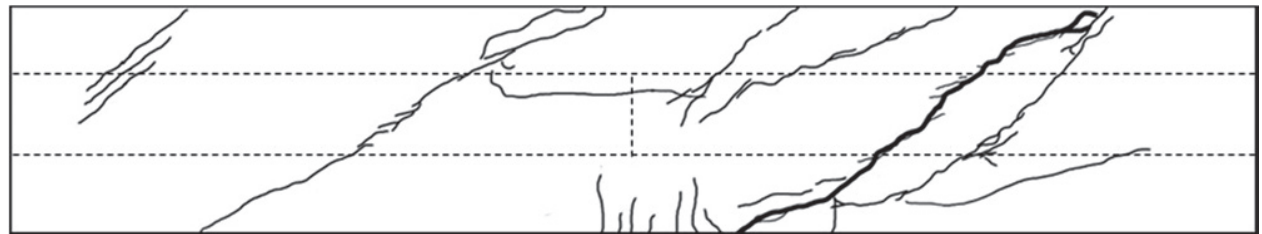

(b)

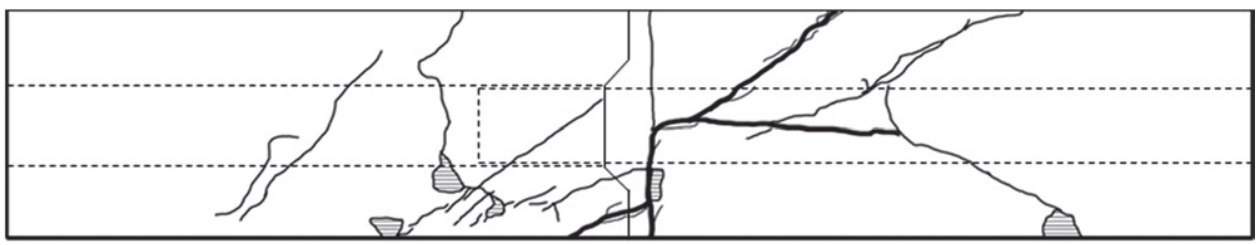

(c)

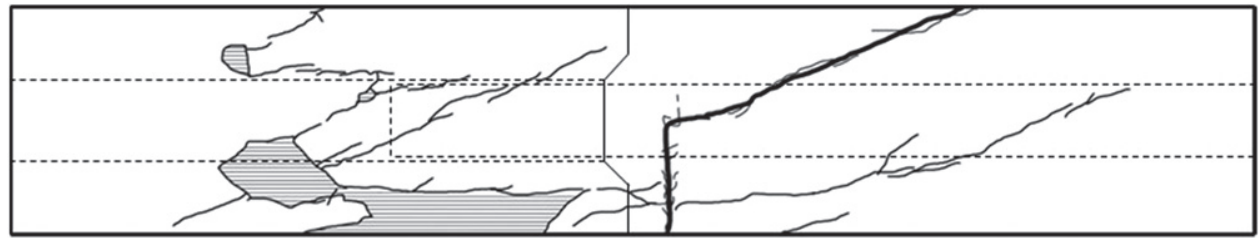

(d)

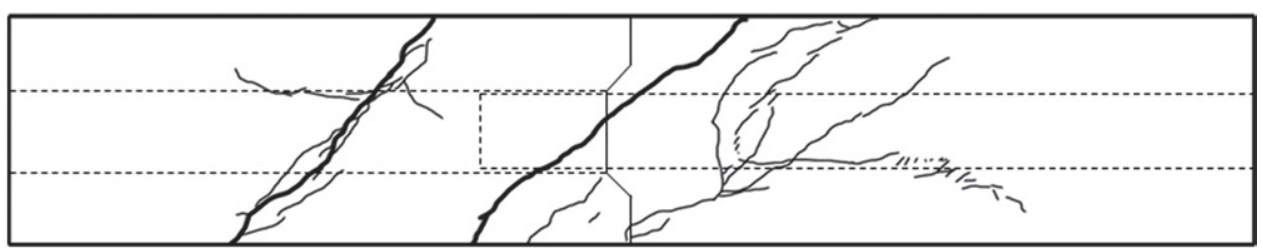

(e)

Figure 1. Crack pattern: (a) MG; (b) SGW; (c) SGI 300; (d) SGI

600; (e) SGC and splice locations 
were obscured by the text boxes for MG and SGW. The figure is reproduced here as Figure 2 to display the obscured data points. Figure 2 clearly demonstrates the improved post-cracking performance of $\mathrm{MG}$ and $\mathrm{SGW}$ compared with the SGI and SGC specimens.

\section{REFERENCE}

Kim MS, Scanlon A, Kang J and Lee YH (2014) Torsional behaviour of prestressed concrete girder with precast box segments. Magazine of Concrete Research 66(11): $576-584$. 